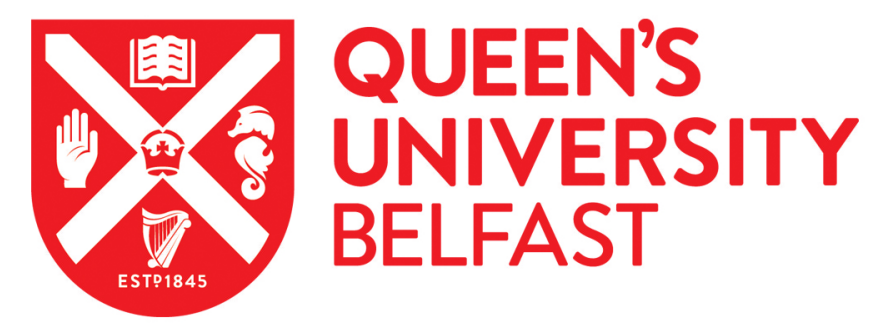

\title{
Mathematical modelling of quantum yield enhancements of methyl orange photooxidation in aqueous TiO2 suspensions under controlled periodic UV LED illumination
}

Tokode, O., Prabhu, R., Lawton, L. A., \& Robertson, P. K. J. (2014). Mathematical modelling of quantum yield enhancements of methyl orange photooxidation in aqueous TiO2 suspensions under controlled periodic UV LED illumination. Applied Catalysis B: Environmental, 156-157, 398-403. https://doi.org/10.1016/j.apcatb.2014.03.046

Published in:

Applied Catalysis B: Environmental

Document Version:

Peer reviewed version

Queen's University Belfast - Research Portal:

Link to publication record in Queen's University Belfast Research Portal

Publisher rights

Copyright @ 2014 Elsevier B.V.

This manuscript version is made available under the CC-BY-NC-ND 4.0 license http://creativecommons.org/licenses/by-nc-nd/4.0/), which permits distribution and reproduction for non-commercial purposes, provided the author and source are cited.

\section{General rights}

Copyright for the publications made accessible via the Queen's University Belfast Research Portal is retained by the author(s) and / or other copyright owners and it is a condition of accessing these publications that users recognise and abide by the legal requirements associated with these rights.

\section{Take down policy}

The Research Portal is Queen's institutional repository that provides access to Queen's research output. Every effort has been made to ensure that content in the Research Portal does not infringe any person's rights, or applicable UK laws. If you discover content in the Research Portal that you believe breaches copyright or violates any law, please contact openaccess@qub.ac.uk. 
1 Mathematical modelling of quantum yield enhancements of methyl orange photooxidation in aqueous $\mathrm{TiO}_{2}$ suspensions under controlled periodic UV LED illumination

4 Oluwatosin Tokode, Radhakrishna Prabhu, Linda A Lawton and Peter K. J.

5 Robertson*.

6 IDeaS, Innovation, Design and Sustainability Research Institute, Robert

7 Gordon University, Schoolhill, Aberdeen, AB10 1FR, UK.

\section{ABSTRACT}

9 Quantum yields of the photocatalytic degradation of methyl orange under 10 Controlled Periodic Illumination (CPI) have been modelled using existing 11 models. A modified Langmuir-Hinshelwood ( $\mathrm{L}-\mathrm{H})$ rate equation was used to 12 predict the degradation reaction rates of methyl orange at various duty 13 cycles and a simple photocatalytic model was applied in modelling quantum 14 yield enhancement of the photocatalytic process due to the CPI effect. A 15 good agreement between the modelled and experimental data was 16 observed for quantum yield modelling. The modified $\mathrm{L}-\mathrm{H}$ model, however, 17 did not accurately predict the photocatalytic decomposition of the dye under 18 periodic illumination.

\section{KEYWORDS}

20 Photocatalysis, Titanium dioxide, Quantum yield, Langmuir-Hinshelwood,

21 Mathematical model

$22 *$ Corresponding author P.K.J. Robertson email: peter.robertson@rgu.ac.uk 


\section{I NTRODUCTION}

24 Semiconductor photocatalysis using titanium dioxide $\left(\mathrm{TiO}_{2}\right)$ photocatalysts

25 is an active area of research in environmental remediation, which has been

26 demonstrated to be effective in the destruction of a variety of environmental

27 pollutants and toxins [1-5]. Photocatalytic detoxification takes place when

28 redox reactions involving charge-carriers $\left(\mathrm{e}_{\mathrm{cb}}^{-}\right.$and $\left.\mathrm{h}^{+}{ }_{\mathrm{vb}}\right)$ are initiated by the

29 absorption of photons of appropriate energy by the photocatalyst/substrate.

30 If the initial photo-excitation takes place in the photocatalyst $\left(\mathrm{TiO}_{2}\right)$, which

31 then transfers energy or an electron to the adsorbed ground state molecule

32 (substrate), a sensitized photo-reaction is said to have taken place. When

33 the reverse takes place, the process is referred to as a catalyzed photo-

34 reaction [6]. Once generated, the fate of the electron-hole pair follows two

35 notable pathways; charge-carrier recombination in the bulk or surface and

36 charge transfer to adsorbed species $\left(\mathrm{H}_{2} \mathrm{O}, \mathrm{OH}^{-}\right.$and $\left.\mathrm{O}_{2}\right)$ producing

37 intermediate species $\left(\mathrm{O}_{2}^{-}\right.$and $\left.\mathrm{OH}^{*}\right)$. The generated $\mathrm{h}^{+}{ }_{\mathrm{vb}}$ and $\mathrm{OH}^{*}$ having

38 redox potentials of +2.53 and +2.27 respectively [7] at $\mathrm{pH} 7$ are highly

39 electropositive and responsible for the photooxidation of adsorbed

40 substrates. Since charge-carrier recombination is a faster primary process

41 than interfacial charge transfer [4], most electron-hole pairs recombine

42 therefore limiting charge transfer which is necessary for initiating the redox

43 reactions required for photocatalytic detoxification. Hence, charge-carrier

44 recombination is the most important primary process limiting the efficiency

45 of the photocatalytic process.

46 The efficiency of photocatalytic oxidation processes is measured as the rate

47 of photocatalytic reaction per photon absorbed by the catalyst. This is the

48 quantum yield $(\varphi)$, which is directly proportional to the electron transfer

49 rate constant $\left(k_{\mathrm{t}}\right)$ and inversely proportional to the charge carrier

50 recombination rate constant $\left(k_{r}\right)(1)$.

51

$$
\varphi \propto \mathrm{k}_{\mathrm{t}} \propto 1 / \mathrm{k}_{\mathrm{r}}
$$

52 In the absence of charge-carrier recombination, the quantum yield, $\varphi$ of an

53 ideal photocatalytic system will be unity (2). $k_{t}$ will depend on migration of

54 charge carriers to the surface and the equalization of electron-hole 
55 concentration such that $\mathrm{e}_{\mathrm{cb}}^{-}=\mathrm{h}_{\mathrm{vb}}^{+}$at the photocatalyst surface. In real

56 photocatalytic systems, however, $\mathrm{e}_{\mathrm{cb}}^{-} \neq \mathrm{h}^{+}{ }_{\mathrm{vb}}$ at the surface.

58 In dilute aqueous solutions, $\varphi$ is typically below $10 \%$ [8] whereas in the gas 59 phase $\varphi$ exceeds $50 \%$ under low intensity illumination [9]. These low 60 quantum yields of $\mathrm{TiO}_{2}$ photocatalytic oxidation prevent its application in 61 large scale water remediation [10]. Determination of $\varphi$ for heterogeneous 62 photocatalysis is a difficult process because of the effects of scattering and 63 reflection of photons by the photocatalyst surface. Therefore, an alternative 64 measure of photocatalytic efficiency which is the photonic efficiency ( $\zeta$ ) can 65 be employed. Photonic efficiency takes into account the number of incident 66 photons and as a result, the measured efficiency is a lower limit of the $\varphi$ 67 for any photocatalytic reaction because of the greater magnitude of photons 68 incident compared with photons absorbed [11].

69 In order to suppress charge-carrier recombination and enhance the 70 efficiency of photocatalytic oxidation Sczechowski et al. [12] suggested the 71 use of controlled periodic (transient) illumination as a means of increasing 72 the efficient use of photons in photocatalysis hence, increasing quantum 73 yield. Controlled periodic illumination (CPI) consist of a series of alternate 74 light and dark periods $\left(t_{\text {light }} / t_{\text {dark }}\right)$ and is based on a hypothesis that 75 continuous introduction of photons may result in the build-up of charges 76 and photogenerated intermediates such as $\mathrm{O}_{2}^{-}$and $\mathrm{OH}^{\circ}$. These species take 77 part in the necessary redox reactions but can also participate in reactions 78 that favour charge-carrier recombination therefore; periodically illuminating 79 the $\mathrm{TiO}_{2}$ particle at short intervals would inhibit the build-up of these species 80 and promote the favourable oxidation process.

81 Previous studies have shown that at equivalent average photon 82 absorption/flux, $\varphi / \zeta$ under periodic illumination do not exceed those under 83 continuous illumination [8]. In a more recent study [13], we showed 84 experimentally that the duty cycle $(\gamma)$ and not the pulse width is responsible 85 for the increase in efficiency of photocatalysis under CPI. In this study, we 86 reproduce the results of our previous experimental study theoretically, 
87 using existing CPI models. The reaction rates at various $\gamma$ are calculated 88 using the modified Langmuir-Hinshelwood rate equation by Chen et al. [14] 89 and $\varphi$ is calculated using the mathematical model developed by Upadhya 90 and Ollis [15].

91 


\section{MATHEMATI CAL MODELS}

93

2.1. Reaction rate modelling

95 For the modelling of photocatalytic reaction rates of methyl orange under $96 \mathrm{CPI}$, the Langmuir-Hinshelwood $(\mathrm{L}-\mathrm{H})$ rate equation (3) was adopted. The $97 \mathrm{~L}-\mathrm{H}$ rate model is the simplest model consistent with Langmuir's equilibrium isotherm and is widely applied to photocatalytic reactions [16-18]. The model interprets the photocatalytic rate of reaction, $r$ as a product of the reaction rate constant, $\mathrm{k}_{\mathrm{r}}$ of surface species (photogenerated and substrate) and the extent of substrate adsorption, $K_{\text {ads }}$. Competition for adsorption by other species is represented by adding the terms $\mathrm{K}_{\mathrm{ads}} \mathrm{C}$ to the denominator.

$$
-\delta \mathrm{C} / \delta \mathrm{t}=\mathrm{r}=\mathrm{k}_{\mathrm{r}} \mathrm{K}_{\mathrm{ads}} \mathrm{C} /\left(1+\mathrm{K}_{\mathrm{ads}} \mathrm{C}\right)
$$

104 Where the rate $r$ is taken as an initial rate $r_{0}, C$ is taken as the equilibrium 105 concentration $\mathrm{C}_{e}, \mathrm{k}_{\mathrm{r}}$ is the reaction rate constant under experimental conditions and $\mathrm{K}_{\mathrm{ads}}$ is the Langmuir adsorption coefficient. However, not all experimental data on photocatalytic reactions can be predicted by this model $[2,19]$. The model is best applied to reactions that follow the pathway of; (i) adsorption of reacting species on the catalyst surface, (ii) reaction involving adsorbed species, (iii) desorption of reaction products.

111 Chen et al. in the decomposition of o-cresol under controlled periodic 112 illumination ( $\mathrm{CPI}$ ) modified the model by incorporating the parameters, 113 which account for the pulsing effect of reactions under CPI [14]. The 114 reaction was assumed to take place on the outer surface of the $\mathrm{TiO}_{2}$ particle 115 and for a photoreactor under periodic illumination, the average light 116 intensity and order of light intensity were incorporated into the rate 117 equation (4) as follows:

$$
-\delta \mathrm{C} / \delta \mathrm{t}=\mathrm{r}_{0}=\mathrm{k}_{\mathrm{r}}\left(\gamma \mathrm{I}_{\max }\right)^{\mathrm{m}} \mathrm{K}_{\mathrm{ads}} \mathrm{C}_{\mathrm{e}} /\left(1+\mathrm{K}_{\mathrm{ads}} \mathrm{C}_{\mathrm{e}}\right)
$$

119 Where $\gamma=\left[\mathrm{t}_{\text {light }} /\left(\mathrm{t}_{\text {light }}+\mathrm{t}_{\text {dark }}\right)\right]$ is the duty cycle of UV illumination and is

120 defined as the ratio of the total illumination period to the total operating 121 period; a duty cycle of 0.5 or $50 \%$ means the lights are on $50 \%$ of the time, $122 I_{\max }$ is the light intensity $\left(I_{a v g}=\gamma I_{\max }\right)$ and $m$ is the order of light intensity. 
$124 \quad 2.2$. Quantum yield modelling

125 Upadhya and Ollis [15] proposed a transient kinetic model to show rapid 126 photooxidation of surface reactants by the oxidizing species $\left(\mathrm{h}^{+}{ }_{\mathrm{vb}}\right)$ accounts 127 for high efficiencies in CPI experiments. The model formulation assumed 128 the entire photocatalytic process to occur on a single $\mathrm{TiO}_{2}$ particle. The 129 factors affecting quantum yield are summarised in the following reactions:

$$
\begin{array}{cr}
\mathrm{TiO}_{2}+\mathrm{hv} \rightarrow \mathrm{e}_{\mathrm{cb}}^{-}+\mathrm{h}^{+}{ }_{\mathrm{vb}} & \text { (light absorption) } \\
\mathrm{e}_{\mathrm{cb}}^{-}+\mathrm{h}^{+}{ }_{\mathrm{vb}} \rightarrow \text { heat (energy) } & \text { (recombination) } \\
\mathrm{h}^{+}{ }_{\mathrm{vb}}+\mathrm{A} \rightarrow \mathrm{A}^{+} & \text {(hole-organic reaction) } \\
\mathrm{e}_{\mathrm{cb}}^{-}+\mathrm{B} \rightarrow \mathrm{B}^{-} & \text {(electron transfer) }
\end{array}
$$

134 The quantum yield, $\varphi$, of the organic substrate was defined as an integral 135 of the instantaneous quantum yield over time;

$$
\varphi=\int k_{1}\left(h^{+}(t)\right) \Omega_{A}(t) \delta t / \int k_{g} l \delta t
$$

137 Where $\mathrm{k}_{1}$ is the oxidation reaction rate constant, $\mathrm{h}^{+}$is the hole 138 concentration, $\Omega_{\mathrm{A}}$ is the surface fractional coverage of organic substrate, $\mathrm{kg}_{\mathrm{g}}$ 139 is the light absorption rate constant and I is the incident light intensity. A 140 high quantum yield will be characterized by a high $\mathrm{h}^{+}$and total surface 141 coverage of the $\mathrm{TiO}_{2}$ particle with reactants. Light and dark periods are 142 incorporated for a $\mathrm{TiO}_{2}$ particle under periodic illumination and the resultant 143 quantum yield is given as:

$$
\begin{gathered}
\varphi_{\text {periodic }}=\int \mathrm{t}_{\text {light }}+\mathrm{t}_{\text {dark }} \mathrm{k}_{1} \mathrm{n}_{\mathrm{A}}\left(\mathrm{h}^{+}(\mathrm{t})\right) \Omega_{\mathrm{A}}(\mathrm{t}) \delta \mathrm{t} / \int^{\mathrm{t} \text { light }} \mathrm{k}_{\mathrm{g}} \mathrm{l} \delta \mathrm{t} \\
\varphi_{\text {continuous }}=\int \mathrm{t}^{\mathrm{t} \text { light }} \mathrm{k}_{1} \mathrm{n}_{\mathrm{A}}\left(\mathrm{h}^{+}\right)_{\mathrm{ss}} \Omega_{\mathrm{Ass}} \delta \mathrm{t} / \int^{\mathrm{t} \text { light }} \mathrm{k}_{\mathrm{g}} \mathrm{l} \delta \mathrm{t}
\end{gathered}
$$

146 Where $\mathrm{n}_{\mathrm{A}}$ is the number of surface sites for organic substrate, $t_{\text {light }}$ is the 147 light time, $t_{\text {dark }}$ is the dark time. The period for the periodic illumination was 
kept constant at $1 \mathrm{~s}$ for different $\gamma$ from $0<\gamma \leq 1$. Hole concentration is a function of time and is described by eq. (12).

$$
\delta\left(h^{+}\right) / \delta t=k_{g} l-k_{r}\left(h^{+}\right)\left(e^{-}\right)-k_{1}\left(h^{+}\right) n_{A} \Omega_{A}
$$

151 2.3. Base case parameter values

152 The same values adopted from the literature by Upadhya and Ollis [15] 153 were used for the constants and parameters in the study. In order to solve 154 (12), a steady state approximation was adopted for electron concentration. 155 It was calculated from typical values of $\mathrm{h}^{+}$quantum yields [20] with the 156 assumption that equal number of holes and electrons are generated. 157 Surface fractional coverage was taken to be constant, and assumed to equal $1587 \times 10^{12} \mathrm{~cm}^{-2}$. Furthermore it is assumed that 50 photons are absorbed in $159 t_{\text {light }}$ of $1 \mathrm{~s}$.

\section{Methodology for quantum yield modelling}

161 The data used in the quantum yield modelling investigated in this study were obtained from experiments carried out in a previous study [13] where three sets of experiments were carried out to investigate the effect of the period, $t_{\text {light }}$ and $t_{\text {dark }}$ on the photonic efficiency of the photocatalytic degradation of methyl orange under low intensity UV light. The experiments were designed using a controlled experimental approach (Table 1.) in order to increase confidence in the outcome of the study.

Table 1.

169 The photonic efficiency remained as the dependent variable throughout the 170 different sets of experiments while the period, $t_{\text {light }}$ and $t_{\text {dark }}$ each served as 171 controlled variables in one set, and independent variable in other sets of 172 experiments, hence providing a critical evaluation of their effects on 173 photonic efficiency. The photonic efficiency, $\zeta$ of the photocatalytic 174 degradation process was calculated as the rate of reaction of the 175 photocatalytic degradation divided by the incident photon rate [21, 22].

$$
\zeta=\frac{\text { Reaction rate }\left(M s^{-1}\right)}{\text { Incident photon rate }\left(M s^{-1}\right)}
$$


177 The reaction rate, $r$ was calculated as change in concentration with time,

$$
r=\frac{\mathrm{C}_{2}-\mathrm{C}_{1}}{\text { Time }}
$$

179 where $C_{1}$ is the concentration at the start of illumination and $C_{2}$ is the final 180 concentration while the incident photon rate from the UV LEDs determined 181 by the ratio of the total energy of the LEDs to the energy of a single photon 182 was calculated to be $4.85 \times 10^{-8}$ einsteins $\mathrm{L}^{-1} \mathrm{~S}^{-1}$.

183 Photonic efficiencies were determined in the experimental study because 184 incident photons were taken into consideration while quantum yields were 185 determined for the theoretical study because the formulation of the 186 mathematical model used was based on photon absorption by the $\mathrm{TiO}_{2}$ 187 catalyst [15]. Hence, in this study, photonic efficiency values are reported 188 for the experimental investigation of methyl orange photooxidation while 189 quantum yield values are reported for the results of the theoretical study. 190 Both results are presented in figures for evaluation of the mathematical 191 model. The data for the experimental determination of $\zeta$ in the experimental 192 study showing the values of $\gamma, t_{\text {light }}$ and $t_{\text {dark }}$ is given in table 2 . The same 193 data was also used in the modelling of $\varphi$ as carried out in the study.

\section{Table 2.}




\section{RESULTS AND DISCUSSION}

\subsection{Photocatalytic rate modelling}

199 The experimental data showed the effect of $\gamma$ on photocatalytic degradation 200 rates of methyl orange. A $5 \mathrm{~g} / \mathrm{L}$ loading of $\mathrm{TiO}_{2}$ was suspended in $100 \mathrm{~mL}$ 201 methyl orange solution in distilled water with an initial concentration of 2.5 $202 \times 10^{-2} \mathrm{mM}$. The photocatalytic degradation of methyl orange solution was 203 carried out over a period of 170 min including $30 \mathrm{~min}$ of dark adsorption 204 which was experimentally determined as the time taken for adsorption 205 equilibrium. Methyl orange photooxidation proceeds by surface-trapped 206 holes which are indistinguishable from $\mathrm{OH}^{*}$ radicals adsorbed on the surface 207 of the hydroxylated $\mathrm{TiO}_{2}$ particle resulting in $\left\{\mathrm{Ti}^{i v} \mathrm{OH}^{*}\right\}^{+}{ }_{\text {ads }}$ which is readily 208 available for oxidative reactions with the surface adsorbed methyl orange $209[23,24]$. The same experimental condition was used for all values of $\gamma$, the 210 period ( $t_{\text {light }}+t_{\text {dark }}$ ) was kept constant while $t_{\text {light }}$ and $t_{\text {dark }}$ were varied. The 211 reaction order $n$ varied with $\gamma$ (Table 3.), I $I_{\max }$ was $<200 \mathrm{Wm}^{-2}$ therefore $\mathrm{m}$ 212 was taken to be first-order [25]. $K_{a d s}$ and $k_{r}$ were obtained from the plot of $2131 / r_{0}$ against $1 / \gamma$, the intercept was equal to $1 / k_{r}$ while the slope provided the 214 solution for $1 / \mathrm{k}_{\mathrm{r}} \mathrm{K}_{\text {ads }}$ hence, the values of $\mathrm{K}_{\mathrm{ads}}$ and $\mathrm{k}_{\mathrm{r}}$ were $0.645 \mathrm{dm}^{3} \mathrm{~mol}^{-1}$ 215 and $4.85 \times 10^{-4} \mathrm{mMmin}^{-1}$ or $\mathrm{min}^{-1}$ with respect to the reaction order.

\section{Table 3.}

217 An increase in photocatalytic rates was observed with increasing $\gamma$ for the 218 experimental and model data (fig. 1). This is because of an increase in the 219 average intensity of illumination. Generally for photocatalytic reactions, a 220 linear relationship exists between photooxidation rates and light intensity 221 at low light intensities. The relationship tends towards a square root 222 relationship as intensity increases and eventually rate becomes 223 independent of intensity at very high intensities [26]. The experimental 224 results however showed a significantly different trend to that obtained with 225 the model. The experimental data exhibited a non-linear trend while the 226 model followed a linear trend. Also, there was a significant difference in the 227 order of magnitude of the determined rates of reaction and this resulted in 228 a poor fit of the experimental data by the model. 
230 Chen et al. who developed and first reported the use of this model reported

231 a good fit to the experimental rates [14]. Their plot involved reaction rates

232 at several concentrations and a single $\gamma$. Our experiments monitored

233 reaction rates at a single concentration but several $\gamma$. The varying $I_{\text {avg }}$ as a

234 result of changing $\gamma$ had a significant influence on the model rates and this

235 accounted for the significant disagreement between the model and

236 experimental rates in trend and magnitude. Photocatalytic reactions under

237 periodic illumination involve complex transient mechanisms therefore

238 developing a model for the dependence of the reaction rate on the

239 experimental parameters over the reaction time can be difficult. The

240 dependence of the constants $K_{a d s}$ and $k_{r}$ on the intensity of UV illumination

241 is well established $(15,16)[27-30]$ and this is not accounted for in the

242 modified L-H model.

245 The variation of the constants $K_{a d s}$ and $k_{r}$ with UV intensity implies their 246 values when obtained from a plot of $1 / r_{0}$ against $1 / \gamma$ will not give a truly 247 representative value for each $\gamma$ in the modified $\mathrm{L}-\mathrm{H}$ model. Furthermore, 248 orders of reaction rate dependence on photon flux and reagent 249 concentration are independent of each other [31]. This presents a problem 250 for the model as reaction order with respect to concentration changes with 251 an effect on $k_{r}$ while order of photon flux remains the same.

\section{3.2. Quantum yield modelling}

253 The quantum yield modelling of the photocatalytic degradation of methyl 254 orange confirmed the same trends from experimental data which were 255 previously reported in the literature [13]. The effect of a constant period 256 and varying $t_{\text {light }}$ and $t_{\text {dark }}$ on the quantum yield was modelled (fig. 2). All 257 events required for photocatalytic oxidation (5-8) were constrained in $1 \mathrm{~s}$ 258 such that $t_{\text {light }}+t_{\text {dark }}=1 \mathrm{~s}$ for all duty cycles. 
260 A general increase in quantum yield as duty cycle decreased was observed 261 indicating an inverse relationship between $\varphi$ and $\gamma$. Quantum yield and 262 photonic efficiency differ because of the difference in accounting for photons, $\varphi$ takes into account the amount of photons absorbed by the catalyst and this is affected by, reflection, transmission and scattering which is significant and can vary as much as $13 \%-76 \%$ depending on experimental conditions [32]. Photonic efficiency on the other hand takes into consideration only the incident photons on the photocatalyst, assuming all photons are absorbed and light-losses are negligible.

The model agreement with the experimental data in the modelling of the effect of $t_{\text {light }}$ and $t_{\text {dark }}$ on $\varphi$ followed a similar trend. When $t_{\text {light }}$ was kept constant while $t_{\text {dark }}$ varied, the contributing effect of $t_{\text {dark }}$ to quantum yield

272 was observed. The approach taken involved the light time events mainly

273 (5) taking place within 1 s therefore having a controlled impact on $\varphi$ while 274 the dark time events were varied by increasing $t_{\text {dark }}$ from $0.1 \mathrm{~s}$ to $1 \mathrm{~s}$, the 275 resulting range for the duty cycle was $\gamma=0.39-0.91$ (fig. 3).

\section{$276 \quad$ Figure 3.}

277 The dark period is devoted to the replenishment of surface adsorbed species

278 by the transfer of electrons to adsorbed oxygen (8) and/or the adsorption 279 of oxygen onto the surface. Consequently, a higher rate constant for these 280 steps will result in higher quantum yields. Figure 3 shows the relatively 281 small improvements in quantum yield as $t_{\text {dark }}$ increases in agreement with 282 previous experimental results. The resulting increase in quantum yield was 283 inferior to the same effect produced by an increasing $t_{\text {light. }}$. This is as a result 284 of the sensitivity of the dark period to the rate-limiting nature of (8) [15, 285 33].

286 In the third modelling result, the experimental light time was varied while 287 the dark time was kept constant. This produced the effect of an increase in $288 \mathrm{I}_{\text {avg }}$ and higher photon absorption by the photocatalyst as $t_{\text {light }}$ increased, 289 without a corresponding increase in $t_{\text {dark. }}$. The modelled results (fig. 4) show 290 the quantum yield improved with decreasing duty cycle. 


\section{$291 \quad$ Figure 4.}

292 As tlight increased, more time was available for (5), which is the first step in 293 the photocatalytic process, giving rise to (6) resulting in a decrease in 294 quantum yield. The modelling further reiterates our previous findings which 295 show that decreasing $t_{\text {light }}$ at constant $t_{\text {dark }}$ has a greater effect on quantum 296 yield than increasing $t_{\text {dark }}$ at constant $t_{\text {light }}$ or varying both alternatively by 297 varying the period.

298 The enhancement observed in the mathematical modelling of $\varphi$ when 299 controlled periodic illumination is employed is produced by the duty cycle, $300 \gamma$, which is a function of $t_{\text {light }}$ and $t_{\text {dark }}$ therefore, their alternating effects 301 contribute to the overall quantum yield enhancement. Figure 5 shows the 302 overall trend of quantum yield enhancement as a result of reducing duty 303 cycle using modelled data. This is in agreement with the result using 304 experimental data [13] depicting a trend of increasing quantum yield as 305 duty cycle decreases irrespective of $t_{\text {light }}$ and $t_{\text {dark }}$.

\section{Figure 5.}




\section{Conclusion}

309 Several mathematical models exist for photocatalytic reactions using $\mathrm{TiO}_{2}$ 310 with light intensity distribution and reactor modelling receiving the most 311 attention. The modified $\mathrm{L}-\mathrm{H}$ rate equation used in the study is the most 312 suitable for modelling photocatalytic reaction rates under controlled periodic 313 illumination because of the integration of $I_{\max }, \mathrm{m}$ and $\gamma$ which account for 314 the UV intensity, order of intensity and periodicity of illumination 315 respectively. The influence of $\gamma$ on the reaction order and the variation of 316 the constants $K_{a d s}$ and $k_{r}$ with UV intensity, however, makes the model 317 suitable only for reactions with a single $\gamma$. The quantum yield model 318 although speculative, gives a good agreement between the trends for the 319 experimental data and model data. This suggests a potential for the 320 formulation of more detailed models which provide a thorough 321 understanding of the CPI effect and the modelling of photocatalytic rates 322 under controlled periodic illumination in the aqueous phase.

\section{Acknowledgement}

324 The authors would like to thank the Scottish Funding Council who funded 325 R. Prabhu's lectureship through the Northern Research Partnership's 326 research pooling initiative in engineering. 


\section{Nomenclature}

329 C Concentration

$330 \quad C_{1} \quad$ Initial concentration

$331 \mathrm{C}_{2} \quad$ Final concentration

$332 \quad C_{e} \quad$ Equilibrium concentration

$333 \mathrm{k}_{\mathrm{r}} \quad$ Reaction rate constant

$334 \mathrm{k}_{1} \quad$ Oxidation reaction rate constant

335 Kads Langmuir adsorption coefficient

$336 \quad \mathrm{~kg}_{\mathrm{g}} \quad$ Light absorption rate constant

$337 \quad I_{\text {avg }} \quad$ Average intensity

$338 I_{\max }$ Maximum intensity

339 I Incident light intensity

$340 \mathrm{~m}$ Order of light intensity

$341 \mathrm{n} \quad$ Order of reaction

$342 \mathrm{n}_{\mathrm{A}} \quad$ Number of surface sites for MO

$343 r_{0} \quad$ Initial reaction rate

$344 \quad r \quad$ Reaction rate

$345 \mathrm{t} \quad$ Time

$346 t_{\text {dark }}$ Dark time

$347 \quad t_{\text {light }}$ Light time

$348 t_{\text {total }}$ Total time

$349 \Omega_{\mathrm{A}} \quad$ Surface fractional coverage by MO 
$350 \mathrm{~h}^{+} \quad$ Hole concentration

$351 \mathrm{e}^{-} \quad$ Electron concentration

$352 \mathrm{k}_{\mathrm{t}} \quad$ Electron transfer rate constant

$353 \mathrm{e}^{-}{ }_{c b} \quad$ Conduction band electron

$354 \quad \mathrm{~h}^{+} \mathrm{vb} \quad$ Valence band holes

355 Greek letters

$356 \gamma \quad$ Duty cycle

$357 \varphi \quad$ Quantum yield

$358 \zeta \quad$ Photonic efficiency

359 Abbreviations

360 MO Methyl orange

361 CPI Controlled Periodic Illumination

362 L-H Langmuir-Hinshelwood

363 
365

366

367

368

369

370

371

372

373

374

375

376

377

378

379

380

381

382

383

384

385

386

387

388

389

390

391

392

393

394

395

[1] P.K.J. Robertson, D.W. Bahnemann, J.M.C. Robertson, F. Wood, in: P. Boule, D.W. Bahnemann, P. K. J. Robertson (Eds.), Environmental Photochemistry Part II, Springer-Verlag Berlin Heidelberg. (2005, pp.) 367-424.

[2] P.K.J . Robertson, L.A. Lawton, B. Munch, J. Rouzade, Chem. Commun. (1997) 393-394.

[3] A. Mills, S. Le Hunte, J. Photochem. Photobiol. A. 108 (1997) 1-35.

[4] M.R. Hoffmann, T.S. Martin, W. Choi, W.D. Bahnemann, Chem. Rev. 95 (1995) 69-96.

[5] D. Bahnemann, D. Bockelmann, R. Goslich, Sol. Energ. Mater. 24 (1991) 564-583.

[6] L.A. Linsebigler, G. Lu, T.J. Yates, Chem. Rev. 95 (1995) 735-758.

[7] A. Fujishima, T.N. Rao, D.A. Tryk, J. Photochem. Photobiol. C:

Photochemistry Reviews. 1 (2000) 1-21.

[8] J.G.C. Cornu, A.J. Colussi, M.R. Hoffmann, J. Phys. Chem. B. 105 (2001) 1351-1354.

[9] Y. Ohko, K. Hashimoto, A. Fujishima, J. Phys. Chem. A. 101 (1997) 8057-8062.

[10] D. Bahnemann, J. Cunningham, M.A. Fox, E. Pelizzetti, P. Pichat, N. Serpone, in: Aquatic and Surface Photochemistry. D. Crosby, G. Helz, R. Zepp (Eds.). Lewis, Boca Raton, FL. (1994) pp. 261-316,

[11] N. Serpone, J. Photochem. Photobiol. A. 104 (1997) 1-12.

[12] J.G. Sczechowski, C.A. Koval, R.D. Noble, J. Photochem. Photobiol. A. 74 (1993) 273-278.

[13] O. Tokode, R. Prabhu, L.A. Lawton, P.K.J. Robertson, J. Catal. 290 (2012) 138-142.

[14] H. Chen, Y. Ku, A. Irawan, Chemosphere. 69 (2007) 184-190.

[15] S. Upadhya, F.D. Ollis, J. Phys. Chem. B. 101 (1997) 2625-2631.

[16] K.V. Kumar, K. Porkodi, F. Rocha, Catal. Commun. 9 (2008) 82-84.

[17] A. Mills, J. Wang, D.F. Ollis, J. Catal. 243 (2006) 1-6.

[18] D. Ollis, Top. Catal. 35 (2005) 217-223. 
[19] S. Valencia, F. Catano, L. Rios, G. Restrepo, J. Marín, Appl. Catal. BEnviron. 104 (2011) 300-304.

[20] K. Ishibashi, A. Fuj ishima, T. Watanabe, K. Hashimoto, J. Photochem. Photobiol. A. 134 (2000) 139-142.

[21] S. Sakthivel, M.V. Shankar, M. Palanichamy, B. Arabindoo, D.W. Bahnemann, V. Murugesan, Water Res. 38 (2004) 3001-3008.

[22] J. Marugán, D. Hufschmidt, G. Sagawe, V. Selzer, D. Bahnemann, Water Res. 40 (2006) 833-839.

[23] O. Tokode, R. Prabhu, L.A. Lawton, P.K.J . Robertson. The effect of pH on the photonic efficiency of the destruction of methyl orange under controlled under periodic illumination with UV-LED sources. Chem. Eng. J . (2014), accepted for publication.

[24] D. Lawless, N. Serpone, D. Meisel, J. Phys. Chem. 95 (1991) 51665170 .

[25] I.K. Konstantinou, T.A. Albanis, Appl. Catal. B-Environ. 49 (2004) 114.

[26] F.D. Ollis, E. Pelizzetti, N. Serpone, Environ. Sci. Technol. 25 (1991) 1522-1529.

[27] D.F. Ollis, J. Phys. Chem. B. 109 (2005) 2439-2444.

[28] Y. Xu, C.H. Langford, J. Photochem. Photobiol. A. 133 (2000) 67-71.

[29] A.V. Emeline, V. Ryabchuk, N. Serpone, J. Photochem. Photobiol. A. 133 (2000) 89-97.

[30] Y.R. Smith, A. Kar, V. Subramanian, Ind. Eng. Chem. Res. 48 (2009) 10268-10276.

[31] A. Emeline, A. Rudakova, V. Ryabchuk, N. Serpone, J. Phys. Chem. B. 102 (1998) 10906-10916.

[32] A. Salinaro, A.V. Emeline, J. Zhao, H. Hidaka, V.K. Ryabchuk, N. Serpone, Pure Appl. Chem. 71 (1999) 321-335.

[33] H. Gerischer, A. Heller, J. Electrochem. Soc. 139 (1992) 113-118. 
427 Table 1: Controlled experimental approach used in obtaining experimental 428 data for quantum yield modelling.

429 Table 2: Values of $\gamma, t_{\text {light }}$ and $t_{\text {dark }}$ used for theoretical modelling of $\varphi$.

430 Table 3: Experimental conditions for methyl orange photooxidation rate 431 under controlled periodic illumination.

432

433 


\begin{tabular}{cccc}
\hline EXPERI MENT & $\begin{array}{c}\text { DEPENDENT } \\
\text { VARI ABLE }\end{array}$ & $\begin{array}{c}\text { I NDEPENDENT } \\
\text { VARI ABLE }\end{array}$ & $\begin{array}{c}\text { CONTROLLED } \\
\text { VARI ABLE }\end{array}$ \\
\hline 1 & $\begin{array}{c}\text { Photonic } \\
\text { Efficiency } \\
\text { Photonic }\end{array}$ & $\mathrm{t}_{\text {light }} / \mathrm{t}_{\text {dark }}$ & Period \\
2 & $\begin{array}{c}\text { Efficiency } \\
\text { Photonic }\end{array}$ & $\mathrm{t}_{\text {dight }} /$ Period & $\mathrm{t}_{\text {dark }} /$ Period \\
\hline
\end{tabular}

441 Table 1.

\begin{tabular}{ccc|ccc|ccc}
\hline \multicolumn{3}{c}{ Varying Period } & \multicolumn{3}{c}{ Varying t light $^{2}$} & \multicolumn{3}{c}{ Varying tdark } \\
$\gamma$ & $\mathrm{t}_{\text {light }}(\mathrm{S})$ & $\mathrm{t}_{\text {dark }}(\mathrm{S})$ & $\gamma$ & $\mathrm{t}_{\text {light }}(\mathrm{S})$ & $\mathrm{t}_{\text {dark }}(\mathrm{S})$ & $\gamma$ & $\mathrm{t}_{\text {light }}(\mathrm{S})$ & $\mathrm{t}_{\text {dark }}(\mathrm{S})$ \\
\hline 0.07 & 0.07 & 0.90 & 0.08 & 0.1 & 1.0 & 0.39 & 1.0 & 1.7 \\
0.12 & 0.12 & 0.86 & 0.21 & 0.3 & 1.0 & 0.44 & 1.0 & 1.4 \\
0.24 & 0.23 & 0.74 & 0.31 & 0.5 & 1.0 & 0.50 & 1.0 & 1.1 \\
0.36 & 0.35 & 0.62 & 0.39 & 0.7 & 1.0 & 0.59 & 1.0 & 0.7 \\
0.49 & 0.47 & 0.50 & 0.50 & 1.1 & 1.0 & 0.67 & 1.0 & 0.5 \\
0.61 & 0.59 & 0.38 & & & & 0.77 & 1.0 & 0.3 \\
0.73 & 0.71 & 0.27 & & & & 0.91 & 1.0 & 0.1 \\
0.85 & 0.83 & 0.15 & & & & & & \\
1.0 & - & - & & & & & & \\
\hline
\end{tabular}

447 Table 2. 
453

454

\begin{tabular}{cccc}
\hline $\boldsymbol{\gamma}$ & $\begin{array}{c}\mathbf{I}_{\text {avg }} \\
\left(\mathbf{W} \mathbf{m}^{-\mathbf{2}}\right)\end{array}$ & $\begin{array}{c}\mathbf{r}_{\mathbf{4 0}} \\
\left(\mathbf{m M m i n}^{-\mathbf{1}}\right)\end{array}$ & $\mathbf{n}$ \\
\hline 0.07 & 0.13 & $2.38 \mathrm{E}-05$ & 0 \\
0.12 & 0.21 & $2.50 \mathrm{E}-05$ & 0 \\
0.24 & 0.43 & $7.50 \mathrm{E}-05$ & 0 \\
0.36 & 0.64 & $1.00 \mathrm{E}-04$ & 0 \\
0.49 & 0.87 & $1.25 \mathrm{E}-04$ & 0 \\
0.61 & 1.09 & $1.50 \mathrm{E}-04$ & 1 \\
0.73 & 1.30 & $1.75 \mathrm{E}-04$ & 1 \\
0.85 & 1.51 & $1.85 \mathrm{E}-04$ & 1 \\
1.00 & 1.78 & $2.11 \mathrm{E}-04$ & 1 \\
\hline
\end{tabular}

455

456 Table 3.

457 


\section{Captions for figures}

459 Figure 1: Correlation of modified L-H model data with experimental for 460 methyl orange degradation rates at different $\gamma$.

461 Figure 2: Decreasing duty cycle resulting in a corresponding rise in quantum 462 yield and photonic efficiency.

463 Figure 3: Contributing effect of $t_{\text {dark }}$ to quantum yield enhancement

464 Figure 4: Contributing effect of $t_{\text {light }}$ to quantum yield enhancement.

465 Figure 5: Overall quantum yield trend as a function of duty cycle with 466 experimental result graph as an insert.

467 


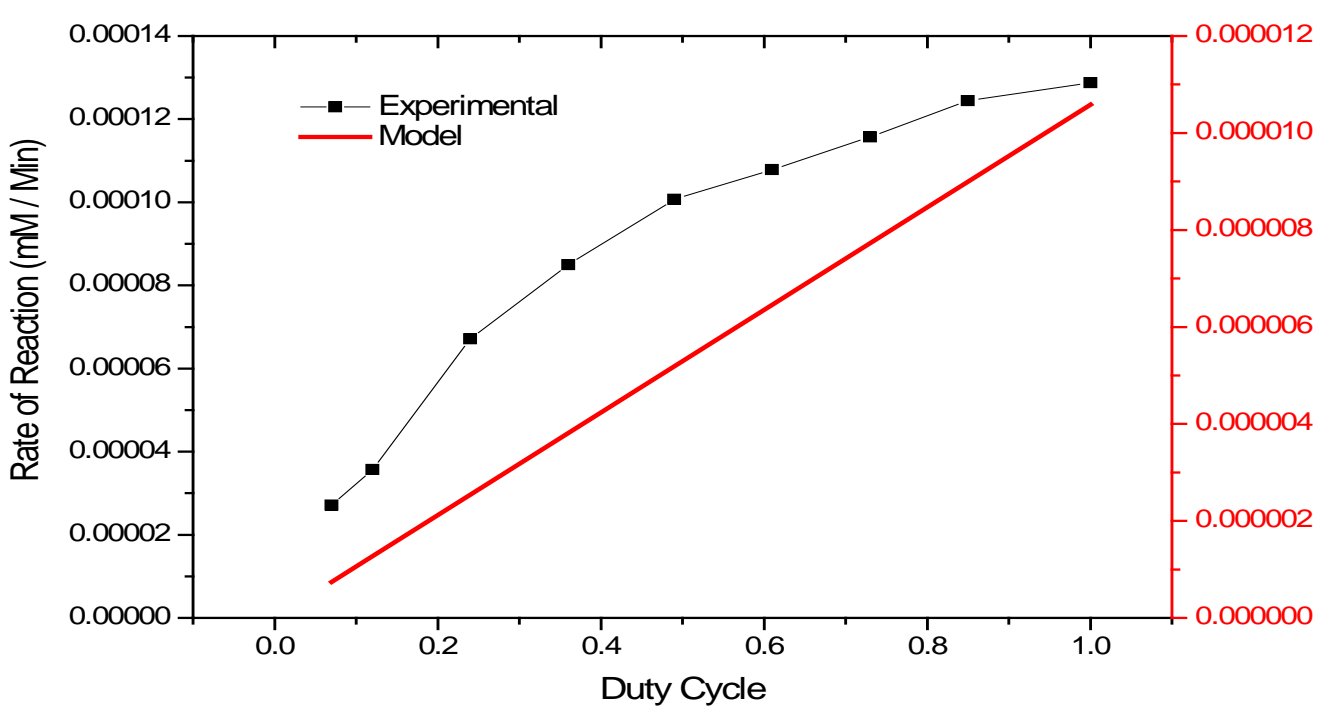

468

469 Figure 1.

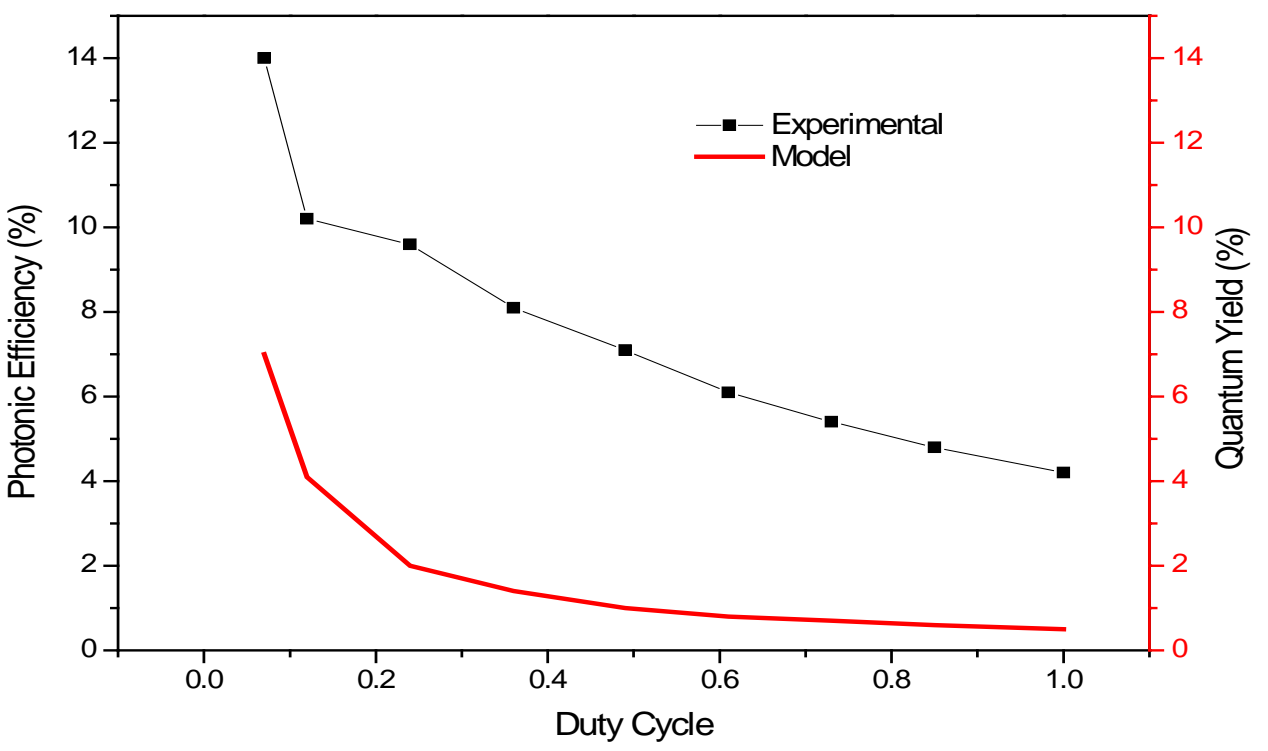

470

471 Figure 2.

472 


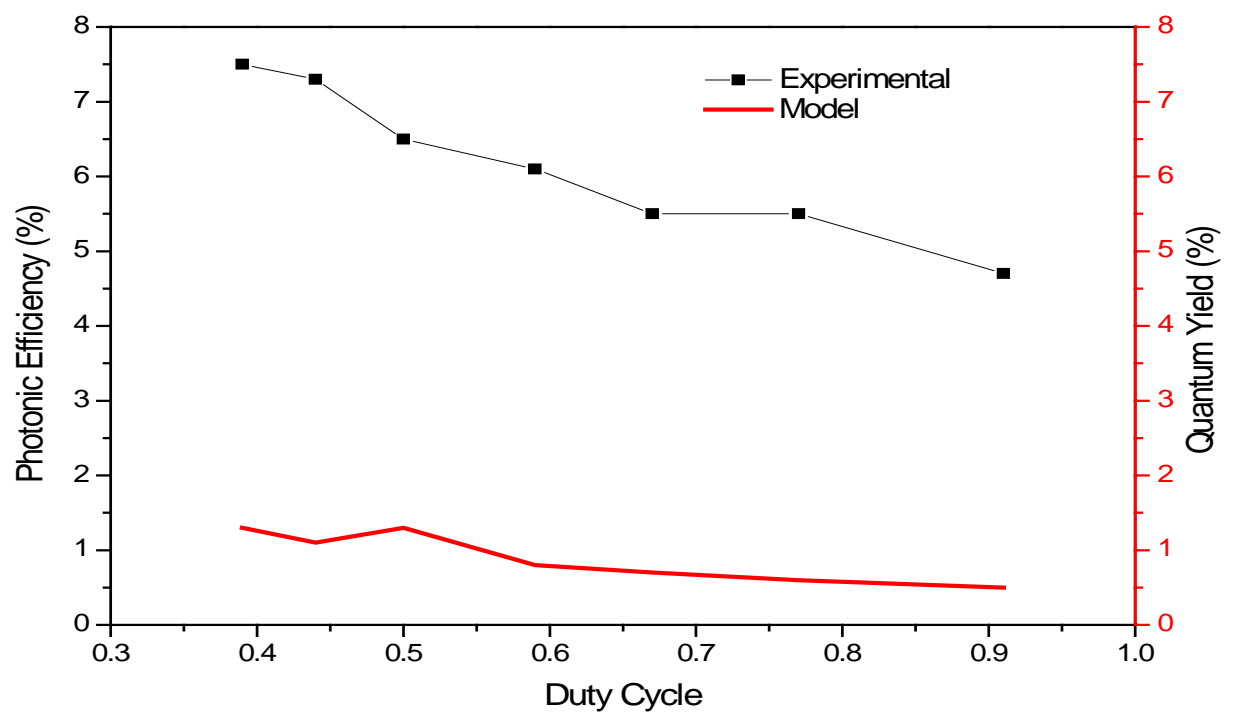

473

474 Figure 3.

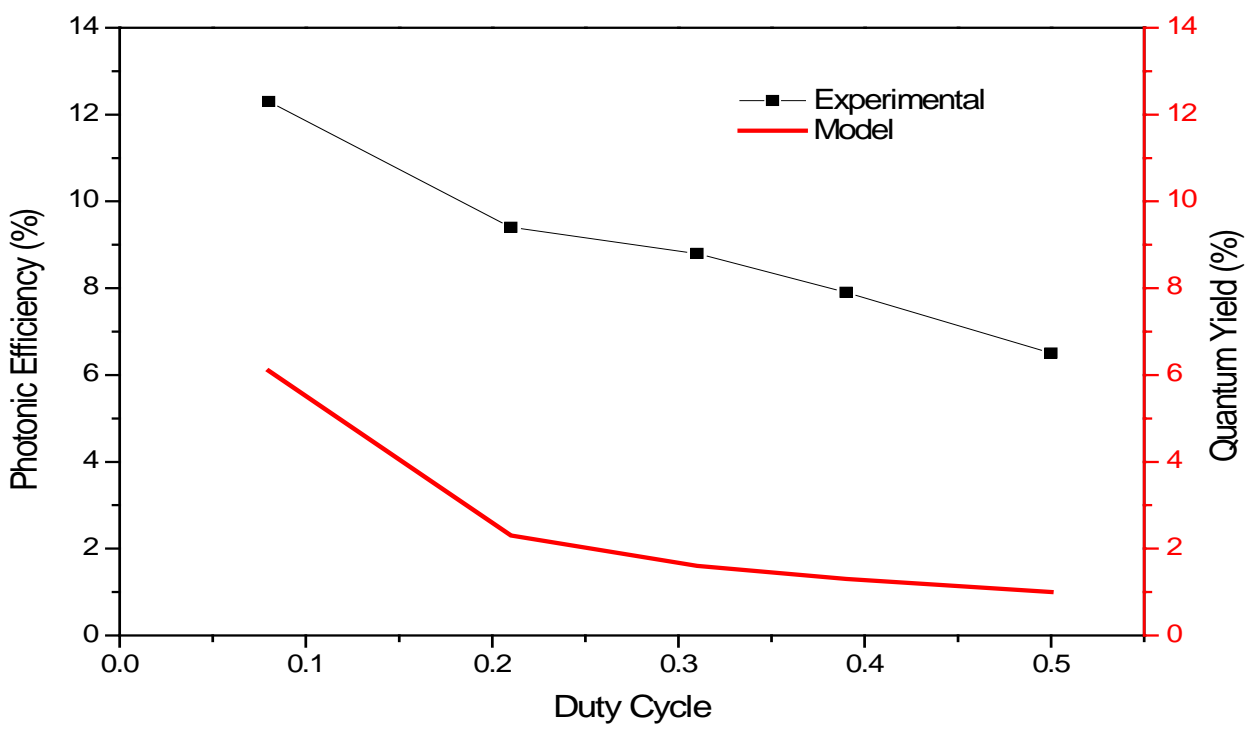

475

476 Figure 4.

477 


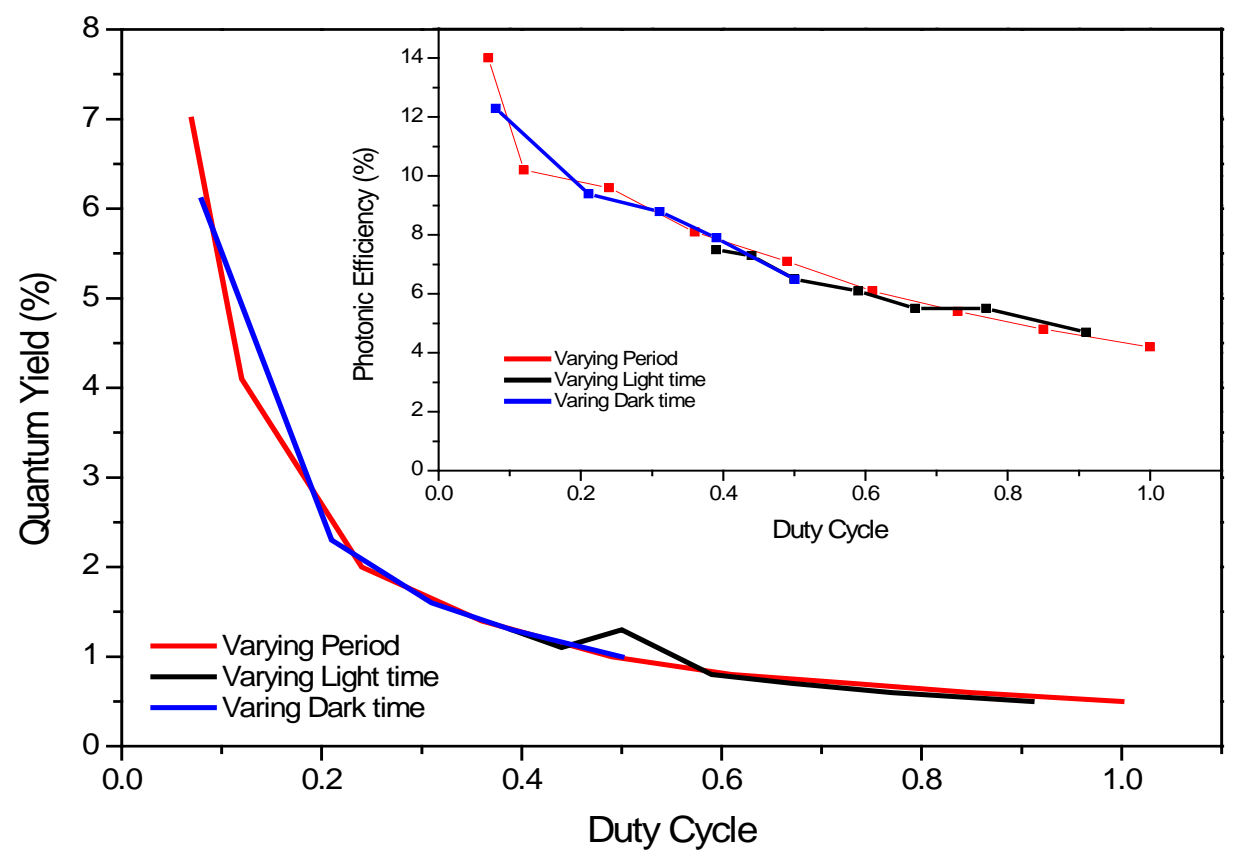

478

479 Figure 5. 